\title{
¿Por qué los cirujanos debemos ser parte de la Sociedad de Cirujanos de Chile?
}

\author{
Why the surgeons must belong to the Society of Surgeons
}

En el necesario e interesante intercambio personal que he tenido con los cirujanos jóvenes de distintas ciudades del país, he podido comprobar que existe una desinformación preocupante respecto de lo que es la Sociedad de Cirujanos, cuáles son sus objetivos y, en definitiva, porqué todos, o al menos la mayoría de los cirujanos que practican esta ciencia-arte debieran estar bajo el alero de la Sociedad.

Al respecto, no debemos olvidar que en la mayoría de los países desarrollados, un especialista no podría ejercer sin la aprobación de un organismo ministerial más la certificación otorgada por la sociedad científica respectiva. Desgraciadamente esto no ocurre en nuestro medio y el marco regulatorio permite que sólo la mitad de los cirujanos en ejercicio pertenezca a la Sociedad de Cirujanos de Chile, institución que supera los 60 años de vida en beneficio de la calidad en la práctica quirúrgica.

En primer lugar, debo señalar que actualmente no es necesario presentar un Trabajo de Ingreso para estos fines y, de acuerdo a los nuevos estatutos de la Sociedad que están aprobados y en espera de completar los trámites legales, la condición de miembro titular será la única posible, desapareciendo la figura del miembro afiliado. Esta exigencia en el pasado ha sido un motivo de desincentivo para muchos colegas que laboran en hospitales pequeños, donde la creación científica es más difícil.

La Sociedad otorga en la actualidad una serie de beneficios que queremos compartir con ustedes. En primer lugar, la entrega regular de la Revista Chilena de Cirugía, órgano de difusión bimensual de la Sociedad que recientemente ha logrado la categoría de publicación ISI al ser aceptada en la SCIE (Science Citation Index Expanded o ISI Web of Science), lo que ciertamente es un paso significativo y nos llena de orgullo. Si bien es cierto, cualquiera puede acceder libremente a ella en internet, algunos colegas todavía valoran la revista impresa y gustan de formar una pequeña biblioteca médica.

La Sociedad de Cirujanos de Chile ofrece un abanico de posibilidades de desarrollo profesional y personal, puesto que incorpora gran parte de las especialidades y sub-especialidades de la cirugía moderna. Así, la Sociedad Chilena de Coloproctología, la Sociedad de Cirugía de Cabeza y Cuello, la Sociedad de Cirugía Plástica y Reconstructiva, la Sociedad Chilena de Quemaduras son agrupaciones autónomas pero muy relacionadas con la Sociedad Madre. Los Departamentos de Cirugía Biliar, Hígado y Páncreas, Cirugía de Tórax, Bariátrica, Mama, Hernia, Cirugía Vascular, Trauma y Departamento de Investigación y Evidencia, desarrollan una vasta labor de capacitación y estímulo entre sus miembros con proyección nacional.

Los cirujanos pueden y deben integrarse a los Capitulos que la Sociedad ha formado y apoyado a lo largo de Chile con el fin de mejorar las condiciones de trabajo y elevar el nivel de la cirugía a través del país, aspecto fundamental para el desarrollo de las máximas capacidades de los socios que laboran en provincia. Actualmente, existen los capitulos de la II, IV, V, VIII, IX y la X-XI Regiones, que cumplen un activo rol cientifico local y que son apoyados desde el punto de vista financiero y académico por la Sociedad.

La participación en el Congreso anual permite a los cirujanos conocer, a través de invitados nacionales y extranjeros los principales avances de la cirugía en los diferentes campos, compartir experiencias, formar lazos de amistad y cooperación y, sin lugar a dudas, ampliar la perspectiva de la práctica quirúrgica en el ámbito local. Esto se traduce en la incorporación de nuevas técnicas y conocimientos que conducen a una cirugía de mejor calidad y en claro beneficio para nuestros pacientes. Un ejemplo paradigmático de ello fue la implementación de un Departamento de Cirugía laparoscópica biliar, que 
en la década del 90 recorrió todo el país difundiendo una técnica que hoy día debiera ser el estándar de oro.

La certificación que entrega la Sociedad de Cirujanos de Chile a sus socios representa una validación del cirujano por sus pares y ello se ha visto potenciado en los llamados a concurso de cargos públicos y en el proceso de normalización de la planta esquemática de los distintos hospitales del país. Esto será especialmente relevante en el proceso de re-certificación que ha iniciado CONACEM, lo que implica justificar frente a un organismo autónomo que las competencias están vigentes y que se han cumplido una serie de etapas en el desarrollo profesional. Al respecto la Sociedad está preparando un curso interactivo a través de la WEB que permitirá obtener créditos y la debida certificación de una actividad que se realiza, completamente "on line".

La Sociedad de Cirujanos de Chile tiene un representante permanente en ASOCIMED (Asociación de Sociedades Médicas), institución que forma parte de CONACEM, la que ha sido un baluarte en la certificación de las especialidades médicas en nuestro medio y en la defensa de estándares mínimos en la formación de los especialistas en Chile.

Sin duda existe una complementariedad entre la labor formativa de las universidades y las sociedades cientificas, cuestión primordial para la Sociedad de Cirujanos de Chile, que se expresa en múltiples actividades, entre otras, sus programas de educación continua para los cirujanos y en forma muy importante gracias a su participación creciente y activa, en conjunto con las universidades, en los organismos encargados de la acreditación y control, lo que debe ser estimulado y reforzado.

Con cierta frecuencia (desgraciadamente en aumento), la Sociedad ha debido nombrar un perito para apoyar la defensa de algunos de nuestros socios que enfrentan una querella en lo penal por supuesta negligencia, siempre con resultados muy satisfactorios para el socio, instancia que es independiente de las acciones que puedan realizar los seguros contratados por el médico.

En definitiva, pertenecer a la Sociedad de Cirujanos creemos que otorga al cirujano un valor agregado en la práctica de la cirugía en nuestro país, representa la mejor manera de mantenerse actualizados y en sintonía con el avance vertiginoso de la tecnología y el conocimiento y, porque no decirlo, un resguardo frente a los avatares de la práctica quirúrgica actual. Creemos firmemente que los jóvenes cirujanos debieran ingresar a la Sociedad inmediatamente luego de haber terminado su Programa de Formación en Cirugía General o haber obtenido el reconocimiento de CONACEM. Necesitamos una Sociedad de cirujanos potente, representativa de todas las vertientes de la actividad quirúrgica nacional, que fomente la calidad de la atención quirúrgica y sea capaz de influir en el desarrollo de la salud del país. Sólo sumando podremos lograr este anhelo.

Dr. Guillermo Bannura Cumsille Presidente de la Sociedad de Cirujanos de Chile 